Marquette University

e-Publications@Marquette

School of Dentistry Faculty Research and

Publications

Dentistry, School of

4-1-2017

Predoctoral Dental Students' Perceptions of Dental Implant Training: Effect of Preclinical Simulation and Clinical Experience

Soni Prasad

Marquette University, soni.prasad@marquette.edu

Naveen K. Bansal

Marquette University, naveen.bansal@marquette.edu

Published version. Journal of Dental Education, Vol. 81, No. 4 (April 2017): 395-403. DOI. (C) 2017

American Dental Education Association. Used with permission. 


\title{
Predoctoral Dental Students' Perceptions of Dental Implant Training: Effect of Preclinical Simulation and Clinical Experience
}

\author{
Soni Prasad, BDS, MS, FACP; Naveen Bansal, BS, PhD \\ Abstract: The aims of this study were to assess 1) differences in perceptions of dental implant training between dental students \\ who received didactic training alone (control group) and those who received didactic plus simulation training (test group); 2) \\ differences in response between students with and without clinical experience in implant dentistry; and 3) the interaction effect \\ of simulation training and clinical experience on students' satisfaction. A survey was distributed to the control group in 2014 and \\ to the test group in 2015; both groups were at the same U.S. dental school. Data were collected on confidence levels with various \\ implant restorative procedures along with overall satisfaction and number of implant restorations performed by each student. The \\ response rate was $78.7 \%$ in the control group and $81.3 \%$ in the test group. In the control group, $85.7 \%$ of students reported being \\ satisfied with implant training compared to $90.8 \%$ of students in the test group. The interaction effect of simulation training and \\ clinical experience on overall student satisfaction was $\mathrm{OR}=1.5$ at $95 \% \mathrm{CI}: 0.8,3.0$. The students who had clinical experience with \\ implant restorative procedures had significantly greater satisfaction than those who did not (OR=4.8, 95\% CI: 2.1, 11.1, p<0.01). \\ This study found that both the simulation and clinical experience affected these students' confidence and satisfaction levels with \\ implant education: they were almost five times more satisfied with implant training when clinical experience in implant restor- \\ ative procedures was a part of their implant education.
}

Dr. Prasad is Assistant Professor, Department of General Dental Science, Marquette University School of Dentistry; and Dr. Bansal is Professor, Department of Mathematics, Statistics, and Computer Science, Marquette University. Direct correspondence to Dr. Soni Prasad, Department of General Dental Science, Marquette University School of Dentistry, 1801 W. Wisconsin Avenue, Milwaukee, WI 53233; 414-288-6515; soni.prasad@marquette.edu.

Keywords: dental education, dental implants, preclinical simulation, implant training

Submitted for publication 5/4/16; accepted 9/2/16

doi: 10.21815/JDE.016.001

$\mathrm{T}$ he increasing popularity of dental implants has increased the demand for dentists who are trained in providing implant treatment. To meet this growing demand, many dental schools have incorporated implant training into their predoctoral curricula. ${ }^{1-5}$ A 2004 survey of U.S. dental school deans found that $97 \%$ of the 39 respondents had implemented didactic instruction in dental implants at their schools, and $86 \%$ reported that their students received clinical experience in restoring implants. ${ }^{1}$ However, deans whose schools provided clinical experience reported that only $51 \%$ of the students actually received clinical experience in restoring implants. Clinical experience in implant restoration was a requirement for graduation in four of the schools, whereas 28 had no such requirement.

Predoctoral dental students who have received laboratory and/or clinical implant experience have been found to be more likely to provide implant treatment in their dental practice after graduation. ${ }^{6,7}$ Therefore, incorporating implant training into predoctoral curricula and establishing competency criteria to assess training are becoming critical. Since 2013, the Commission on Dental Accreditation (CODA) has required all graduating dental students to be competent in providing implant restorative treatment for their patients. ${ }^{8}$ However, in annual surveys of dental school seniors over the past several years, implant dentistry has been one of top areas in which students perceived that the time spent in the curriculum was inadequate. ${ }^{9,10}$ Challenges identified in establishing implant instruction in predoctoral dental education are cost for implementation, limited funding, patient availability, and limited time in the curriculum. ${ }^{5,11-13}$

Initially, implant dentistry training was predominantly didactic in nature. ${ }^{14}$ In medical education, Swamy et al. found that the transition from didactic training to clinical training was a major source of stress for students. ${ }^{15}$ To resolve this problem, instructional methods slowly evolved to incorporate a combination of didactic and simulation training, thereby linking knowledge with clinical practice. In Swamy et al.'s study, simulation training helped with the transition and introduced generic clinical skills in such a way that students were able to apply their knowledge to practice. 
Simulation training has been found to be popular with students in both medicine and dentistry. ${ }^{15-17}$ Reasons given for its popularity have been that simulation training enabled learners to develop clinical skills without fear of harm to patients, helped with retention of didactic information and repetition of critical skills, and increased student motivation and satisfaction. Students' ability to apply knowledge in clinical situations has been found to improve, ${ }^{18}$ along with teamwork and self-evaluation. ${ }^{19}$ With simulation training, students' confidence in application and execution of knowledge improved tremendously in one study. ${ }^{18}$

Although prior research has addressed the importance of simulation training and clinical experience, no studies have assessed the effect of both on students' perception of training. Furthermore, no previous study has investigated the individual effect of simulation training and clinical experience and the combined interaction effect of both on students' perception of their implant education. The aims of our study were thus to assess 1) differences in perceptions of implant training between dental students at Marquette University School of Dentistry who received didactic training only (control group) and those who received didactic plus simulation training (test group); 2) differences in response between students with and without clinical experience in implant dentistry; and 3) the interaction effect of simulation training and clinical experience on students' satisfaction.

\section{Materials and Methods}

The study was found to be exempt from oversight by Marquette University's Internal Review Board. The preclinical implant program at Marquette University School of Dentistry was established in 2014. Prior to 2014, implant training consisted of didactic lectures given in various courses throughout the curriculum. The hands-on component consisted of a half-day course conducted by an implant company in the summer of the second year.

The aims of the new interdisciplinary preclinical implant program were threefold: to provide indepth didactic training on various aspects of implant dentistry (diagnosis, treatment planning, implant placement, and implant restoration); to provide hands-on training in implant restorative procedures including surgical guide fabrication, single implant crown, and implant overdentures; and to establish preclinical competence in implant restorative procedures at the predoctoral level. The preclinical implant course consists of a ten-week program and includes 22.5 hours of didactic instructions and 39.5 hours of simulation exercise in implant restorative procedures. The course covers various topics on implant dentistry including diagnosis and treatment planning, site evaluation and planning using cone bean computed tomography (CBCT), knowledge of implant software, surgical guide fabrication, implant placement in fake mandible, fabrication of custom abutments and provisional implant restoration, implant overdenture, and chair-side pick-up of Locator attachments. Students are also taught to perform implant maintenance and recognize implant complications. At the end of the course, the students' preclinical competence is assessed with a multiplechoice written exam and a four-hour practical exam. Students are granted access to treat implant patients in the clinic after being assessed as successful on the written and practical exams.

In the clinic, students review the patient's health history, perform intraoral examinations, and make radiographs as required by the case. Based on the location of the proposed implant, a CBCT is utilized for site evaluation. A diagnostic tooth setup of the missing dentition is performed, and after initial consent from the patient, an implant board is scheduled with the student, patient, restorative faculty member, and oral and maxillofacial surgeon. All the parties involved review the case, and the consent for treatment is signed. Students fabricate surgical guides for their patients and perform try-ins to verify the fit intraorally. A CBCT-generated guide is used in selective cases such as sites with limited bone height and width. Experienced surgeons place all implants, and students assist during the surgery. After osseointegration, implants are restored by the students under faculty supervision. A radiograph is taken on the day of abutment/crown delivery as a baseline for future follow-up.

For the study, a survey was distributed to two consecutive classes of graduating seniors. The Class of 2014 was the control group, which received implant training in didactic lectures only, and the Class of 2015 was the test group, which had both didactic and preclinical simulation training. Both the test and control groups had similar didactic training on various aspects of implant restoration. There were 80 students in each group.

The survey consisted of 21 questions grouped into four domains that aimed to collect information 
on aspects of implant treatment: diagnosis and treatment planning, surgical guide fabrication, restorative procedures, stress level experienced by students while performing the procedures, and overall satisfaction with the implant training. There were five response options for each question with $5=$ highest and $1=$ lowest. The number of fixed and/or removable implant restorations performed by each student was also recorded. The survey was completely anonymous and voluntary.

The survey responses were treated as ordinal variables and entered into an SPSS database, version 22 (IBM, Chicago, IL, USA). Median and frequency percentages were calculated, and the data were analyzed descriptively. Bivariate descriptive analysis was used to study difference between control and test groups with and without clinical experience. Ordinal logistic regression was used to test association between preclinical simulation training and clinical experience on students' satisfaction with implant education. Statistical significance was set at $\alpha=0.05$. To avoid issues due to small sample size, significance was confirmed by Fisher's exact test $(p<0.01)$.

\section{Results}

In the control group, 63 students responded to the survey for a response rate of $78.7 \%$; in the test group, 65 responded for a response rate of $81.3 \%$. Among the responding students in the control group, $51(81 \%)$ had clinical experience with implant restorative procedures at the time of graduation, while 12 $(19 \%)$ had no clinical experience in restoring either fixed or removable implant restoration. Among the responding students in the test group, $47(72 \%)$ reported having clinical experience at the time of graduation, while $18(28 \%)$ did not.

\section{Descriptive Analysis}

The responses strongly agree, agree, and somewhat agree were combined into a total agreement response for each question by each participating student. In the control group, the percentages of students who reported being confident in treatment planning a single implant crown (SIC) and an implant overdenture (IOD) were $41.3 \%(n=26)$ and $69.3 \%(n=43)$, respectively. In the test group, $44.6 \%(n=29)$ students reported being confident in treatment planning an SIC restoration, and $76.9 \%$ $(n=50)$ reported being confident in treatment plan- ning an IOD. Regarding using CBCT for diagnosis and treatment planning, $90.3 \%(\mathrm{n}=56)$ students in the control group and $95.4 \%(n=62)$ in the test group reported being confident.

When students were asked their perception of the importance of a surgical guide in implant dentistry, $36 \%(n=23)$ of those in the control group and $43 \%(n=28)$ in the test group agreed that a surgical guide was important. There was a difference in response between control group $(25 \%, \mathrm{n}=15)$ and test group students $(52.4 \%, \mathrm{n}=33)$ when asked if they had fabricated a surgical guide for all their implant patients. Also, $75 \%(n=45)$ of students in the control group and $87.3 \%(n=55)$ in the test group reported trying-in their surgical guide and taking a verification radiograph prior to implant placement. Half of the students in the control group $(50 \%, \mathrm{n}=30)$ and $74.2 \%$ $(n=46)$ in the test group reported that the surgical guide they fabricated was used during the implant placement surgery. In addition, $51.7 \%(\mathrm{n}=38)$ of students in the control group and $69.5 \%(n=41)$ in the test group reported feeling they were adequately trained in fabricating a surgical guide for an SIC, whereas $77.4 \%(n=48)$ in the control group and $80 \%$ $(n=52)$ in the test group reported feeling adequately trained in fabricating a surgical guide for an IOD.

Students who reported being confident in making implant level impressions for an SIC were $33.3 \%(\mathrm{n}=21)$ in the control group and $78 \%(\mathrm{n}=27)$ in the test group. Also, 71.4\% $(\mathrm{n}=45)$ in the control group and $72.3 \%(n=47)$ in the test group reported feeling adequately trained in selecting implant parts to restore an SIC, and $62.9 \%(\mathrm{n}=39)$ in the control group and $65.6 \%(n=42)$ in the test group reported feeling adequately trained in fabricating a custom abutment for an SIC.

When asked about their comfort and confidence level in restoring an IOD, 74\% $(\mathrm{n}=50)$ in the control group and $83.8 \%(n=54)$ in the test group reported being comfortable and confident. Also, 85.2\% $(n=52)$ of students in the control group said they could accurately select Locator attachment cuff height, and $83.6 \%(n=51)$ said they felt competent in picking up attachments intraorally. In the test group, 92.3\% $(n=60)$ of the students said they could accurately select the Locator cuff height, and $89.2 \%(n=58)$ said they felt competent in picking up attachments intraorally. In addition, $58.7 \%(\mathrm{n}=37)$ of students in the control group and $67.7 \%(n=44)$ in the test group reported feeling they were adequately trained in the implant follow-up procedure. In the control group, 
$47.6 \%(n=30)$ perceived they were adequately trained in performing an SIC restoration in their practice compared to the test group $(49.2 \%, \mathrm{n}=32)$, and $80.6 \%$ $(n=50)$ in the control group perceived they were adequately trained in performing an IOD restoration in their practice compared to $84.6 \%(n=55)$ in the test group.

Regarding stress levels experienced by the students while providing implant restorations for their patients, $69.5 \%(n=41)$ of students in the control group said they felt stressed when restoring an SIC compared to $68.7 \%(n=44)$ in the test group, whereas $72.3 \%(n=34)$ in the control group said they felt stressed when restoring an IOD compared to $71.4 \%$ $(n=40)$ in the test group. Overall, $85.7 \%(n=54)$ of students in the control group reported being satisfied with the implant education received at their school compared to $90.8 \%(n=59)$ in the test group.

\section{Bivariate Descriptive Analysis}

Total agreement scores of students who had clinical experience in implant restoration compared with those who did not are shown in Table 1. The test group students who had clinical experience in implant restorative procedure responded better than the control group students who had clinical experience in all but one domain. The domain that did not have a higher response in the test group was stress: $42.5 \%$ of students in the test group with clinical experience reported being stressed while performing SIC restorative procedures compared to $43.1 \%$ in the control group with clinical experience. Also, $57.4 \%$ of students in the test group who had clinical experience reported to being stressed while performing IOD restorative procedures compared to $33.3 \%$ in the control group. With the exception of stress level experienced by the students, the test group with clinical experience had the highest confidence and satisfaction with implant restorative procedures, and the control group without any clinical experience had the lowest confidence and satisfaction response. The same trend was seen in overall satisfaction with implant education in the predoctoral clinic (Figure $1)$. In the control group, $45.1 \%(n=23)$ of students with clinical experience reported being satisfied with their implant education compared to $16.7 \%$ $(n=2)$ without clinical experience. In the test group, $55.2 \%(n=25)$ of students with clinical experience reported being satisfied with their implant education compared to $22.2 \%(n=4)$ of students without clinical experience.

\section{Ordinal Regression Analysis}

Table 2 shows the effect of simulation, clinical experience, and interaction of both on students' satisfaction responses. Results are expressed as odds ratio (OR) and associated 95\% confidence interval (CI). Simulation training had a significant effect on responses to questions $5(\mathrm{OR}=0.3, \mathrm{p}=0.01), 7$ $(\mathrm{OR}=0.4, \mathrm{p}=0.04), 8(\mathrm{OR}=1.9, \mathrm{p}=0.05), 9(\mathrm{OR}=2.8$, $\mathrm{p}<0.01)$, and $16(\mathrm{OR}=0.5, \mathrm{p}=0.05)$. Simulation training did not have a significant effect on students' stress levels (Q19: $\mathrm{OR}=1.2, \mathrm{p}=0.5$; $\mathrm{Q} 20$ : $\mathrm{OR}=1.3, \mathrm{p}=0.5$ ). The overall satisfaction with implant training was not significant when only simulation training was taken into consideration $(\mathrm{Q} 21$ : $\mathrm{OR}=0.9, \mathrm{p}=0.3)$.

Clinical experience had a significant effect on students' responses to questions $1(\mathrm{OR}=4.1, \mathrm{p}=0.01)$, $5(\mathrm{OR}=5.7, \mathrm{p}<0.01), 7(\mathrm{OR}=3.4, \mathrm{p}<0.01), 8(\mathrm{OR}=4.9$, $\mathrm{p}<0.01), 10(\mathrm{OR}=9.1, \mathrm{p}<0.01), 11(\mathrm{OR}=4.4, \mathrm{p}<0.01)$, $12(\mathrm{OR}=5.8, \mathrm{p}<0.01), 16(\mathrm{OR}=4.3, \mathrm{p}<0.01)$, and 17 $(\mathrm{OR}=7.7, \mathrm{p}<0.01)$. Similar to simulation training, clinical experience also failed to show a significant effect on students' stress levels (Q19: $\mathrm{OR}=0.6, \mathrm{p}=0.2$; $\mathrm{Q} 20: \mathrm{OR}=1.1, \mathrm{p}=1.0)$. However, clinical experience had a significant impact on overall students' satisfaction with implant education (Q21: $\mathrm{OR}=4.8, \mathrm{p}<0.01)$.

The interaction effect was seen in the group that had both simulation training and clinical experience. A significant interaction effect was observed for questions $8(\mathrm{OR}=3.4, \mathrm{p}<0.01)$ and $9(\mathrm{OR}=2.5, \mathrm{p}=0.01)$. The interaction of simulation and clinical experience on students' overall satisfaction with implant training was $\mathrm{OR}=1.5, \mathrm{p}=0.2$.

\section{Discussion}

Our study found that simulation and clinical experience in implant restorative procedures had a positive effect on these students. The test group, which received simulation training, reported being more confident than the control group on the majority of the questions. However, the difference between the control and test groups was significant for only five questions (Q5: $\mathrm{p}<0.01, \mathrm{Q} 7 \mathrm{p}=0.04, \mathrm{Q} 8: \mathrm{p}=0.05$, Q9: $\mathrm{p}<0.01, \mathrm{Q} 16: \mathrm{p}=0.05)$. The test group also had a higher overall satisfaction response than the control group (control $45.1 \%$ vs. test $55.2 \%$ ). Results from the ordinal regression analysis showed that students in the test group were two times more likely to be confident in fabricating a surgical guide for an SIC $(\mathrm{OR}=1.9,95 \% \mathrm{CI}=1.0,3.6)$ and almost three times more confident in fabricating a surgical guide for 
Table 1. Agreement responses of test and control groups with and without clinical experience in implant restoration, by number and percentage of each group

Control Group Test Group

\begin{tabular}{|c|c|c|c|c|}
\hline Question & $\begin{array}{l}\text { Clinical. Exp. } \\
\qquad N=51\end{array}$ & $\begin{array}{l}\text { No Clinical Exp. } \\
\qquad N=12\end{array}$ & $\begin{array}{c}\text { Clinical Exp. } \\
N=47\end{array}$ & $\begin{array}{l}\text { No Clinical Exp. } \\
\qquad N=18\end{array}$ \\
\hline \multicolumn{5}{|c|}{ Diagnosis and treatment planning } \\
\hline Q1 & $46(90.2 \%)$ & $7(58.3 \%)$ & $44(93.6 \%)$ & $12(66.7 \%)$ \\
\hline Q2 & $26(50.9 \%)$ & $7(58.3 \%)$ & $25(53.2 \%)$ & $12(66.7 \%)$ \\
\hline Q3 & $12(23.5 \%)$ & $1(8.3 \%)$ & $12(25.5 \%)$ & $3(16.7 \%)$ \\
\hline \multicolumn{5}{|c|}{ Surgical guide } \\
\hline Q4 & $42(82.3 \%)$ & $9(75.0 \%)$ & $42(89.4 \%)$ & $14(77.8 \%)$ \\
\hline Q5 & $40(78.4 \%)$ & $3(2.05 \%)$ & $38(80.9 \%)$ & $6(33.3 \%)$ \\
\hline Q6 & $14(27.4 \%)$ & $1(8.3 \%)$ & $15(31.9 \%)$ & $3(16.7 \%)$ \\
\hline Q7 & $31(60.8 \%)$ & $3(25.0 \%)$ & $29(61.7 \%)$ & $5(27.8 \%)$ \\
\hline Q8 & $39(76.5 \%)$ & $2(16.7 \%)$ & $40(85.1 \%)$ & $11(61.1 \%)$ \\
\hline Q9 & $14(27.5 \%)$ & $3(25.0 \%)$ & $30(63.8 \%)$ & $10(55.6 \%)$ \\
\hline \multicolumn{5}{|c|}{ Restorative procedures } \\
\hline Q10 & $45(88.2 \%)$ & $6(50.0 \%)$ & $42(89.4 \%)$ & $9(50.0 \%)$ \\
\hline Q11 & $36(70.5 \%)$ & $5(41.7 \%)$ & $34(72.3 \%)$ & $8(44.4 \%)$ \\
\hline Q12 & $32(62.7 \%)$ & $3(25.0 \%)$ & $27(65.8 \%)$ & $4(22.2 \%)$ \\
\hline Q13 & $20(39.2 \%)$ & $3(25.0 \%)$ & $24(51.0 \%)$ & $7(38.9 \%)$ \\
\hline Q14 & $14(27.5 \%)$ & $4(33.3 \%)$ & $16(34.0 \%)$ & $6(33.3 \%)$ \\
\hline Q15 & $20(39.2 \%)$ & $3(25.0 \%)$ & $19(40.4 \%)$ & $8(44.4 \%)$ \\
\hline Q16 & $41(80.4 \%)$ & $7(58.3 \%)$ & 39 (82.9\%) & $10(55.6 \%)$ \\
\hline Q17 & $41(80.4 \%)$ & $4(33.3 \%)$ & $39(82.9 \%)$ & $7(38.9 \%)$ \\
\hline Q18 & $20(39.2 \%)$ & $4(33.3 \%)$ & $19(40.4 \%)$ & $8(44.4 \%)$ \\
\hline \multicolumn{5}{|c|}{ Stress level } \\
\hline Q19 & $22(43.1 \%)$ & $2(16.7 \%)$ & $20(42.5 \%)$ & $10(55.6 \%)$ \\
\hline Q20 & $17(33.3 \%)$ & $2(16.7 \%)$ & $27(57.4 \%)$ & $10(55.6 \%)$ \\
\hline \multicolumn{5}{|c|}{ Overall satisfaction } \\
\hline Q21 & $23(45.1 \%)$ & $2(16.7 \%)$ & $25(55.2 \%)$ & $4(22.2 \%)$ \\
\hline \multicolumn{5}{|c|}{$\begin{array}{l}\text { Note: The responses strongly agree, agree, and somewhat agree were combined into a total agreement response. Questions were as } \\
\text { follows: 1) You are confident in diagnosing and treatment planning a single implant crown, 2) You are confident in diagnosing and } \\
\text { treatment planning an implant overdenture case, 3) You have adequate training in using CBCT for implant planning, 4) You believe } \\
\text { surgical guide is very important in implant dentistry, 5) For how many implant patients did you fabricate a surgical guide, 6) You tried } \\
\text { the guide and took a verification radiograph prior to the surgery, 7) The guide you fabricated was used during implant surgery, 8) You are } \\
\text { adequately trained in surgical guide fabrication of a single implant crown, 9) You are adequately trained in surgical guide fabrication of } \\
\text { an implant overdenture, 10) You have adequate training in making implant impression for single implant crown, 11) You have adequate } \\
\text { training in selecting implant parts required to restore a single implant crown, 12) You have adequate training in fabricating custom abut- } \\
\text { ment for single implant crown, 13) You are trained in using Locator attachments for implant overdenture, 14) You can accurately select } \\
\text { Locator abutment cuff height for your overdenture patients, 15) You feel competent in intra-oral pick up of Locator attachments, 16) } \\
\text { You are adequately trained in implant follow-up procedures, 17) You are adequately trained in performing single implant restoration in } \\
\text { your practice, 18) You are adequately trained in performing implant overdenture restoration in your practice, 19) You felt stressed when } \\
\text { restoring a single implant crown, 20) You felt stressed when performing an implant overdenture restoration, 21) Overall, you are satisfied } \\
\text { with the implant restorative training you received at school. }\end{array}$} \\
\hline
\end{tabular}

an IOD $(\mathrm{OR}=2.8,95 \% \mathrm{CI}=1.5,5.4)$. Our study confirmed the results reported by previous studies. Temmerman et al. investigated students' perception of implant education that consisted of didactic lectures, preclinical hands-on, and clinical experience and reported a high student satisfaction level of $80 \% .{ }^{20}$ Another study from the Netherlands reported similar results. ${ }^{21}$ Kido et al. studied the changes in students' opinion regarding implant education pre and post training and found a decrease in negative responses in the post-training survey compared to the pre-training survey. ${ }^{22}$

We found that clinical experience had a significant effect on students' responses in both the test and control groups. The difference in overall satisfaction was also significant between the group that had clinical experience and the group that did not $(p<0.01)$. Students who had clinical experience 


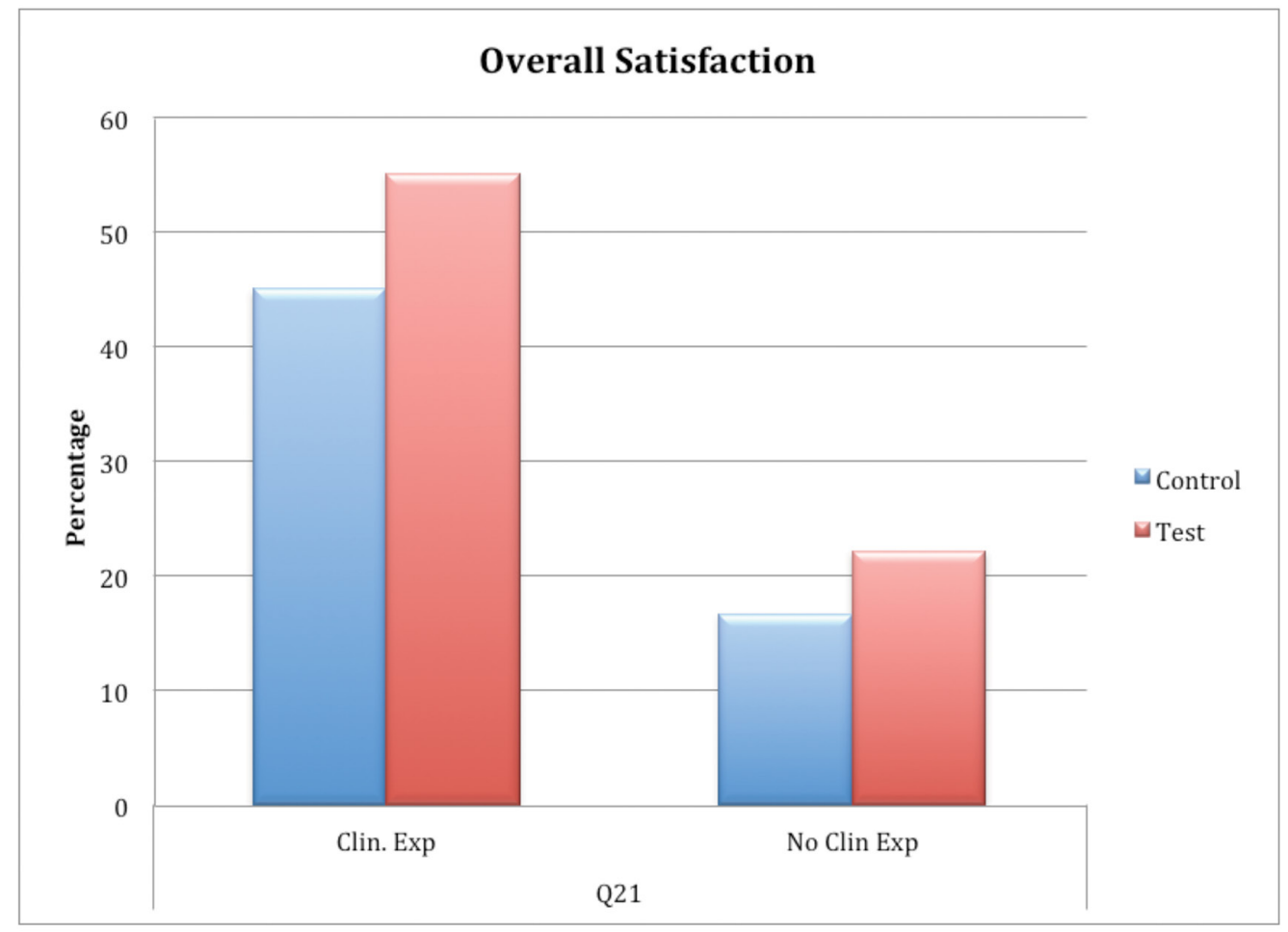

Figure 1. Overall students' satisfaction with their predoctoral implant education, by control and test cohorts who had/ did not have clinical experience

were four times more confident in diagnosis and treatment planning an SIC case than those who did not have any clinical experience. Also, the students who had clinical experience were six times more confident in fabricating a surgical guide for their patients and were almost five times more confident in fabricating a surgical guide for single implant crowns. Students with clinical experience were nine times more confident in making implant impression for an SIC and four times more confident in selecting implant parts for restoring an SIC. Those who had clinical experience were four times more confident than those without clinical experience in performing follow-up procedures for their implant patients and eight times more confident in treating a patient with an SIC in their private practice. Overall, students who had clinical experience were five times more satisfied with their implant education than those students with no clinical experience prior to graduation.

These findings confirmed results from other studies that found clinical experience was a critical component of implant education and contributed to success in implant treatment with reduced failure rates and fewer complications..$^{13,23-25}$ Studies have also found high patient and student satisfaction when clinical experience was a part of implant training in the predoctoral clinic. ${ }^{12,13,23}$

Although the interaction effect of simulation and clinical experience did not show significant impact on several responses in our study, reasonable speculations can be made based on the OR values of each question. For example, although simulation training and clinical experience did not show a significant effect on responses to question 1 , the OR value of 1.7 suggests those students were twice as likely to be confident in diagnosis and treatment planning an SIC than students who did not have both simulation training and clinical experience. Similar speculations can be made based on the OR values of questions $10,11,12,13,17$, and 21 , suggesting better responses from students who had both simulation and clinical experience. The OR value of overall satisfaction (Q21) in the interaction effect group was 1.5 at $95 \%$ CI $(0.8,3.0)$. These findings might imply that students who received both simulation training and clinical experience were 1.5 times more likely to be 


\begin{tabular}{|c|c|c|c|}
\hline Question & $\begin{array}{c}\text { Effect of Simulation Training } \\
\text { OR }(95 \% \mathrm{Cl})\end{array}$ & $\begin{array}{c}\text { Effect of Clinical Experience } \\
\text { OR }(95 \% \mathrm{Cl})\end{array}$ & $\begin{array}{l}\text { Interaction Effect } \\
\text { OR }(95 \% \mathrm{Cl})\end{array}$ \\
\hline \multicolumn{4}{|c|}{ Diagnosis and treatment planning } \\
\hline Q1 & $0.9(0.4,1.5)$ & $4.1(1.8,9.2)^{*}(p=0.01)^{* *}$ & $1.7(0.9,3.3)$ \\
\hline Q2 & $0.8(0.4,1.4)$ & $0.5(0.2,1.1)$ & $0.7(0.4,1.3)$ \\
\hline Q3 & $0.9(0.3,1.2)$ & $1.5(0.7,3.4)$ & $0.9(0.5,1.7)$ \\
\hline \multicolumn{4}{|c|}{ Surgical guide } \\
\hline Q4 & $0.8(0.5,1.6)$ & $0.8(0.4,1.8)$ & $0.9(0.5,1.7)$ \\
\hline Q5 & $0.3(0.2,0.7)^{*}(p<0.01)^{* *}$ & $5.7(2.3,13.4)^{*}(p<0.01)^{* *}$ & $0.8(0.4,1.6)$ \\
\hline Q6 & $0.6(0.3,1.3)$ & $2.7(0.9,8.2)$ & $0.9(0.4,1.9)$ \\
\hline Q7 & $0.4(0.2,0.7)^{*}(p=0.04)^{* *}$ & $3.4(1.4,8.1)^{*}(p<0.01)^{* *}$ & $0.7(0.4,1.4)$ \\
\hline Q8 & $1.9(1.0,3.6)^{*}(p=0.05)^{* *}$ & $4.9(2.2,11.0)^{*}(p<0.01)^{* *}$ & $3.4(1.7,6.7)^{*}(p<0.01)^{* *}$ \\
\hline Q9 & $2.8(1.5,5.4)^{*}(p<0.01)^{* *}$ & $0.8(0.4,1.7)$ & $2.5(1.3,4.9)^{*}(p=0.01)^{* *}$ \\
\hline \multicolumn{4}{|c|}{ Restorative procedures } \\
\hline Q10 & $0.7(0.4,1.3)$ & $9.1(3.9,21.3)^{*}(p<0.01)^{* *}$ & $1.8(0.9,3.5)$ \\
\hline Q11 & $0.7(0.4,1.3)$ & $4.4(2.0,9.8)^{*}(p<0.01)^{* *}$ & $1.4(0.7,2.7)$ \\
\hline Q12 & $0.7(0.4,1.4)$ & $5.8(2.5,13.4)^{*}(p<0.01)^{* *}$ & $1.8(0.9,3.4)$ \\
\hline Q13 & $1.6(0.8,3.0)$ & $1.0(0.5,2.2)$ & $1.5(0.8,3.0)$ \\
\hline Q14 & $1.0(0.6,2.0)$ & $0.8(0.4,1.6)$ & $1.0(0.6,2.0)$ \\
\hline Q15 & $0.9(0.5,1.8)$ & $0.9(0.4,2.0)$ & $0.9(0.5,1.8)$ \\
\hline Q16 & $0.5(0.3,1.0)^{*}(p=0.05)^{* *}$ & $4.3(1.9,9.8)^{*}(p<0.01)^{* *}$ & $1.1(0.6,2.1)$ \\
\hline Q17 & $0.7(0.4,1.4)$ & $7.7(3.3,17.8)^{*}(p<0.01)^{* *}$ & $1.8(1.0,3.4)$ \\
\hline Q18 & $0.9(0.5,1.8)$ & $0.9(0.5,2.1)$ & $1.1(0.6,2.1)$ \\
\hline \multicolumn{4}{|c|}{ Stress level } \\
\hline Q19 & $1.2(0.7,2.4)$ & $0.6(0.3,1.4)$ & $0.9(0.5,1.8)$ \\
\hline Q20 & $1.3(0.6,2.6)$ & $1.1(0.5,2.4)$ & $1.3(0.6,2.6)$ \\
\hline \multicolumn{4}{|c|}{ Overall satisfaction } \\
\hline Q21 & $0.9(0.4,1.4)$ & $4.8(2.1,11.1)^{*}(p<0.01)^{* *}$ & $1.5(0.8,3.0)$ \\
\hline \multicolumn{4}{|c|}{ Note: See note with Table 1 for questions. } \\
\hline $\begin{array}{l}* \text { Significan } \\
* * \text { Significa }\end{array}$ & ct test $(p<0.01)$ for small sam & & \\
\hline
\end{tabular}

satisfied with their implant education. However, lack of significance makes this interpretation speculative rather than definitive, and caution should be exercised in interpreting the result. Our study found that, in both the control and test groups, students who had clinical experience did better than those who with no clinical experience. However, with simulation training, the difference in responses between students with and without clinical experience was reduced considerably.

Predoctoral implant education has changed dramatically in the past years, with increased patient demands heightening the expectation that dental schools will prepare adequately trained graduates. ${ }^{2,3}$ Our study demonstrated the value of simulation training for these predoctoral students and the importance of increasing the number of clinical experiences for students. Simulation training has been found to help students learn necessary skills that are reinforced with clinical experience.${ }^{15}$ In our study, the students had better understanding of the interrelationship between surgical placements and implant restoration with clinical experience. More importantly, they understood the importance of treatment planning prior to surgery and recognized that implant placement was a restoratively driven discipline. In addition, simulation training with clinical experience helped students to understand the importance of patient selection and to identify difficult cases for referral, thus training novice dental professionals to be safe beginning practitioners.

Our study found that students who had clinical experience were five times more likely to be satisfied with the implant education they received. However, $19 \%$ of students in the control group and almost $28 \%$ in the test group graduated without getting any clinical experience in implant restoration. An 
important finding to note was that although the test group had a greater percentage of students than the control group without any clinical experience prior to graduation, that group still had a higher satisfaction response on several of the survey questions, indicating the positive effect of simulation training on the test group. We can speculate that, in the future, simulation training along with increased clinical experience may improve students' overall confidence and satisfaction level. However, further studies are required to substantiate this speculation.

A previous study suggested that, in the absence of clinical experience, a curriculum that included both didactic and laboratory participation still significantly increased the number of graduates who provided implant treatment in their practices. ${ }^{6}$ However, according to our results, although simulation training helped improve the students' overall satisfaction response, the difference in the satisfaction response was not significant. The difference became significant only when students had clinical experience in implant procedures.

Our study did not find any effect of simulation training or clinical experience on the stress level of these students. Students who received both simulation training and clinical experience would be expected to experience less stress. However, there was a consistent stress level for both students with and without simulation training and clinical experience. Previous studies have found multiple factors that contribute to dental students' stress, including examinations, performance pressure, workload, clinical training, and patient treatment. ${ }^{26,27}$ Other studies found that stress increased with pressure to complete treatment in time for graduation and greater faculty expectations. ${ }^{28,29}$ Stress was also found to increase gradually among senior dental students due to an expectation of completing clinical requirements consistently. ${ }^{30}$ Our study did not investigate the specific reasons for students' perceived stress level while performing implant restorative procedures. Perhaps increasing the number of clinical experiences in implant restorative procedures may help in reducing stress levels among the students.

The lack of clinical experience in both the test and control groups in our study is concerning and could be due to multiple barriers such as patient availability and financial limitations. One approach to overcome this barrier would be to establish partnerships with implant companies in the future to reduce the implant treatment cost and increase patients' ability to afford such treatment. ${ }^{12}$
Limitations of our study included the fact that the effect of multiple clinical experiences in implant restoration was not investigated and the reason for a higher stress level among the test group students was not determined. Also, a pre-assessment survey was not administered, and the effect of simulation course grade on satisfaction was not accounted for. Since the study took place at only one dental school, its findings may not be generalizable to students at other schools. Future studies are needed with a validated questionnaire to avoid potential bias in survey responses.

\section{Conclusion}

In this study, we found that both simulation and clinical experience affected the predoctoral dental students' confidence and satisfaction levels regarding their implant education. Students who had simulation training with clinical experience responded better in almost all categories of implant restorations than those without simulation training or clinical experience. Students with clinical experience reported having almost five times' greater confidence and satisfaction with implant education. This difference was found to decrease when simulation training was introduced in the predoctoral curriculum.

\section{Acknowledgments}

The authors wish to acknowledge Dr. Christopher Okunseri and Dr. Pradeep Bhagavatula for their support and statistical expertise and Dr. Frederick Sutkiewicz for providing exit survey data for the study.

\section{REFERENCES}

1. Petropoulos VC, Arbree NS, Tarnow D, et al. Teaching implant dentistry in the predoctoral curriculum: a report from the ADEA implant workshop's survey of deans. J Dent Educ 2006;70(5):580-8.

2. Weintraub AM, Seckinger R, Berthold P, Weintraub GS. Predoctoral implant dentistry programs in U.S. dental schools. J Prosthodont 1995;4(2):116-21.

3. Wilcox CW, Huebner GR, Mattson JS, et al. Placement and restoration of implants by predoctoral students: the Creighton experience. J Prosthodont 1997;6(1):61-5.

4. Lim MV, Afsharzand Z, Rashedi B, Petropoulos VC. Predoctoral implant education in U.S. dental schools. J Prosthodont 2005;14(1):46-56.

5. McAndrew R, Ellis J, Lynch CD, Thomason M. Embedding implants in undergraduate dental education. Br Dent J 2010;208(1):9-10. 
6. Huebner GR. Evaluation of a predoctoral implant curriculum: does such a program influence graduates' practice patterns? Int J Oral Maxillofac Implants 2002;17(4): 543-9.

7. Yuan JC, Kaste LM, Lee DJ, et al. Dental student perceptions of predoctoral implant education and plans for providing implant treatment. J Dent Educ 2011;75(6):750-60.

8. Commission on Dental Accrediation. Accreditation standards for dental education programs. Chicago: American Dental Association, 2013.

9. Garrison GE, Lucas-Perry E, McAllister DE, et al. Annual ADEA survey of dental school seniors: 2013 graduating class. J Dent Educ 2014;78(8):1214-36.

10. Wanchek T, Cook BJ, Anderson EL, Valachovic RW. Annual ADEA survey of dental school seniors: 2015 graduating class. J Dent Educ 2016;80(5):612-29.

11. De Bruyn H, Koole S, Mattheos N, Lang NP. A survey on undergraduate implant dentistry education in Europe. Eur J Dent Educ 2009;13(Suppl 1):3-9.

12. Jahangiri L, Choi M. A model for an integrated predoctoral implant curriculum: implementation and outcomes. J Dent Educ 2008;72(11):1304-17.

13. Koole S, De Bruyn H. Contemporary undergraduate implant dentistry education: a systematic review. Eur J Dent Educ 2014;18(Suppl 1):11-23.

14. Koole S, Vandeweghe S, Mattheos N, De Bruyn H. Implant dentistry education in Europe: 5 years after the Association for Dental Education in Europe consensus report. Eur J Dent Educ 2014;18(Suppl 1):43-51.

15. Swamy M, Bloomfield TC, Thomas RH, et al. Role of SimMan in teaching clinical skills to preclinical medical students. BMC Med Educ 2013;13:20.

16. von der Heyden M, Meissner K. Simulation in preclinical emergency medicine. Best Pract Res Clin Anaesthesiol 2015;29(1):61-8.

17. Buchanan JA. Use of simulation technology in dental education. J Dent Educ 2001;65(11):1225-31.

18. Allen KL, More FG. Clinical simulation and foundation skills: an integrated multidisciplinary approach to teaching. J Dent Educ 2004;68(4):468-74.
19. Pasquale SJ. Educational science meets simulation. Best Pract Res Clin Anaesthesiol 2015;29(1):5-12.

20. Temmerman A, Meeus M, Dhondt R, et al. Oral implant placement and restoration by undergraduate students: clinical outcomes and student perceptions. Eur J Dent Educ 2016;20(2):73-83.

21. Fijnheer C, Langhorst FR, Wismeijer D. Evaluation of the implant-related restorative undergraduate programme at ACTA, the Netherlands. Part I: students' satisfaction. Eur J Dent Educ 2016;20(2):84-93.

22. Kido H, Yamamoto K, Kakura K, et al. Students' opinion of a predoctoral implant training program. J Dent Educ 2009;73(11):1279-85.

23. Vandeweghe S, Koole S, Younes F, et al. Dental implants placed by undergraduate students: clinical outcomes and patients' and students' perceptions. Eur J Dent Educ 2014;18(Suppl 1):60-9.

24. Kronstrom M, McGrath L, Chaytor D. Implant dentistry in the undergraduate dental education program at Dalhousie University. Part 1: clinical outcomes. Int J Prosthodont 2008;21(2):124-8.

25. Parrish L, Hunter R, Kimmes N, et al. Predoctoral dental implant education at Creighton University School of Dentistry. J Dent Educ 2013;77(5):576-80.

26. Polychronopoulou A, Divaris K. Dental students' perceived sources of stress: a multi-country study. J Dent Educ 2009;73(5):631-9.

27. Alzahem AM, van der Molen HT, Alaujan AH, et al. Stress amongst dental students: a systematic review. Eur J Dent Educ 2011;15(1):8-18.

28. Morse Z, Dravo U. Stress levels of dental students at the Fiji School of Medicine. Eur J Dent Educ 2007;11(2): 99-103.

29. Murphy RJ, Gray SA, Sterling G, et al. A comparative study of professional student stress. J Dent Educ 2009;73(3):328-37.

30. Abu-Ghazaleh SB, Sonbol HN, Rajab LD. A longitudinal study of psychological stress among undergraduate dental students at the University of Jordan. BMC Med Educ 2016;16:90. 